TITLE:

\title{
Multiple Steady-States in a Heat Integrated Distillation Column (HIDiC)
}

$\operatorname{AUTHOR}(\mathrm{S}):$

Kano, Manabu; Fukushima, Tomohiro; Makita, Hiroshi; Hasebe, Shinji

\section{CITATION:}

Kano, Manabu ... [et al]. Multiple Steady-States in a Heat Integrated Distillation Column (HIDiC). J ournal of Chemical Engineering of Japan 2007, 40(10): 824-831

\section{ISSUE DATE:}

2007

URL:

http://hdl.handle.net/2433/85264

\section{RIGHT:}

Copyright @ 2007 The Society of Chemical Engineers, Japan; この論文 は出版社版でありません。引用の際には出版社版をご確認ご利用くだ さい。; This is not the published version. Please cite only the published version. 


\title{
Multiple Steady-States in a Heat Integrated Distillation Column (HIDiC)
}

\author{
Manabu KANO*, Tomohiro FUKUSHIMA, Hiroshi MAKITA and Shinji HASEBE \\ Department of Chemical Engineering, Kyoto University, \\ Kyotodaigaku-Katsura, Nishikyo-ku, Kyoto-shi, Kyoto 615-8510, Japan \\ * Tel: 075-383-2687, Fax: 075-383-2657, Email: manabu@cheme.kyoto-u.ac.jp
}

Keywords: Heat Integrated Distillation Column, Multiple Steady-States, Instability Condition, Energy Savings, Compressor

A heat integrated distillation column (HIDiC) is a new and highly energy-efficient distillation process. In the present work, multiple steady-states in HIDiC are analyzed. In HIDiC, the pressure in the rectifying section is kept higher than that in the stripping section by using a compressor to enhance heat transfer from the rectifying section to the stripping section through the wall. Therefore, an energy balance, particularly the influence of the compressor, must be taken into account for the analysis. In this research, two types of operation policies are investigated: P1) constant compressor power and P2) constant pressure ratio. First, the conditions for making multiple steady-states are derived on the basis of the first principle model of the HIDiC. Then, the analysis results are validated through simulations. The results show that: 1) the instability condition depends largely on the compressor operation policies; 2) in case P1, multiple steady-states appear when the top product is highly pure, the bottom product is relatively impure, vapor flow rate is large, and compressor power is small; 3) in case P2, multiple steady-states appear when the bottom product is highly pure; and 4) multiple steady-states appear in a wider range of operation in case P2 than in case P1.

\section{Introduction}

As global warming continues to pose more and more serious problems, the demand to suppress greenhouse gases has increased and led to technological development to achieve energy savings in industries. Since distillation, which is the most widely-used separation process, is quite energy-intensive and accounts for a large part of industrial energy consumption, the development of an energy-efficient distillation process is crucial.

A heat integrated distillation column (HIDiC) is an energy-efficient distillation column that has the potential for drastically reducing energy consumption (Takamatsu et al., 1996). The basic concept of the HIDiC is that the heat duty needed in a reboiler and a condenser can be reduced simultaneously by enhancing internal heat integration. In the last decade or so, basic characteristics and energy savings of the HIDiC have been investigated vigorously. These researches include exergy-based analysis of the energy savings of the ideal HIDiC (Takamatsu et al., 1997), analysis of energy savings in a multicomponent separation process (Iwakabe et al., 2004), and detailed design in which the material transfer rate, heat transfer rate, and pressure drop are taken into account (Noda et al., 2004).

Other critical issues concerning HIDiC are its operability and controllability because internal heat integration and the complex structure of HIDiC might make its operation more difficult than conventional distillation columns. Nakaiwa et al. (1998) investigated the operation of ideal HIDiC that does not have both a reboiler and a condenser. In their work, the top and bottom product compositions were controlled by manipulating the pressure difference and the feed thermal condition, and several control algorithms were compared in performance by using a dynamic model. Liu and Qian (2000) reported the simulation results on dynamics and control of an internally thermally coupled distillation column (ITCDIC), which is basically the same as the ideal HIDiC. They used multiloop PID control, in which the top and bottom product compositions were controlled by manipulating the pressure and the feed thermal conditions. In addition to such simulation-based studies, Naito et al. (2000) investigated a bench-scale ideal HIDiC. To operate the bench-scale ideal HIDiC, two tray temperatures were controlled by manipulating the pressure difference and the feed thermal conditions. They succeeded in operating the bench-scale ideal HIDiC for more than $10 \mathrm{~h}$ without a reboiler and a condenser. The recent efforts to investigate dynamics and control of the HIDiC have been reviewed by Nakaiwa et al. (2003). In addition, Fukushima et al. (2006) investigated and compared the energy savings, dynamics, and controllability of various structures of HIDiCs.

In the present work, the characteristics of HIDiC are analyzed from a different viewpoint; multiple steady-states in HIDiC are analyzed. The main objective of this research is to derive the conditions for making multiple steady-states appear on the basis of a first principle model of the HIDiC. In addition, the analysis results are validated through simulations.

\section{Dynamic Model of HIDiC}

In this section, the structures of HIDiC and ideal HIDiC are shown and the models for simulations are briefly described.

\subsection{Structure of HIDiC}

A schematic diagram of HIDiC is shown in Figure 1. HIDiC has a compressor and a throttling valve between 
the bottom of the rectifying section and the top of the stripping section. Vapor rising from the top of the stripping section is pressurized by the compressor and supplied to the bottom of the rectifying section. Liquid flowing from the bottom of the rectifying section is supplied to the top of the stripping section through a throttling valve. The feed is supplied to the top of the stripping section.

In a conventional column, heat is transferred by a reboiler and a condenser. In the HIDiC, on the other hand, the rectifying section and the stripping section are in physical contact, and the pressure in the rectifying section is kept higher than that in the stripping section by a compressor to enhance heat transfer from the rectifying section to the stripping section through the wall. By this internal heat transfer, vapor in the rectifying section condenses and liquid in the stripping section evaporates. As a result, the heat duty needed in the reboiler and the condenser can be reduced and high energy savings can be achieved. Although a compressor is required in the HIDiC, energy consumption by the compressor is less than that reduced in both the reboiler and the condenser. Therefore, the HIDiC is more energy-efficient than conventional distillation columns.

Figure 2 shows a schematic diagram of an ideal HIDiC (i-HIDiC) that does not have both a reboiler and a condenser. For the column to operate without a reboiler and a condenser, i.e., to achieve an appropriate heat balance, the feed needs to be preheated before entering into the column. Fukushima et al. (2006) investigated several other structures of HIDiC. An i-HIDiC (HX) is an extension of the $\mathrm{i}-\mathrm{HIDiC}$, in which the feed is preheated by distillate vapor (product) to enhance the energy savings. An i-HIDiC (L) is an i-HIDiC with a condenser to improve the controllability.

The present work focuses on the HIDiC shown in Figure 1.

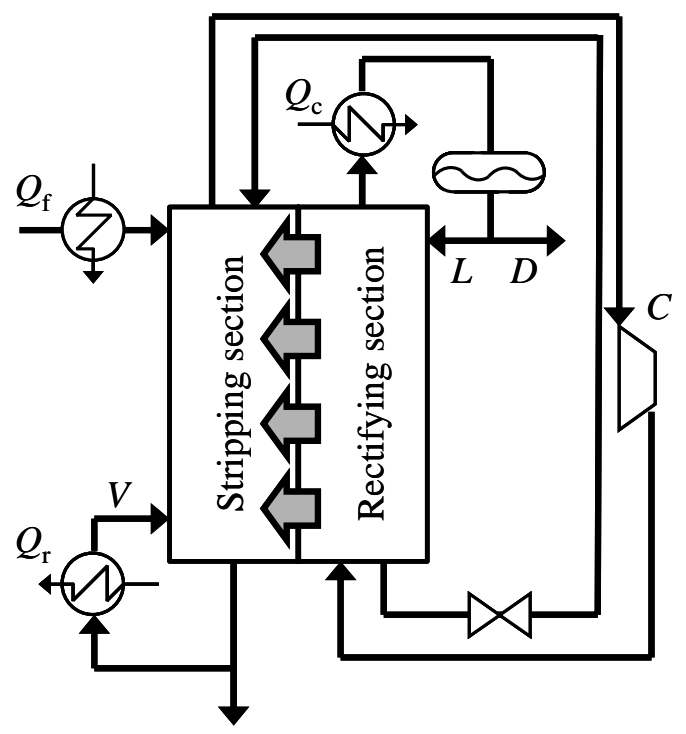

Fig. 1 Schematic diagram of HIDiC

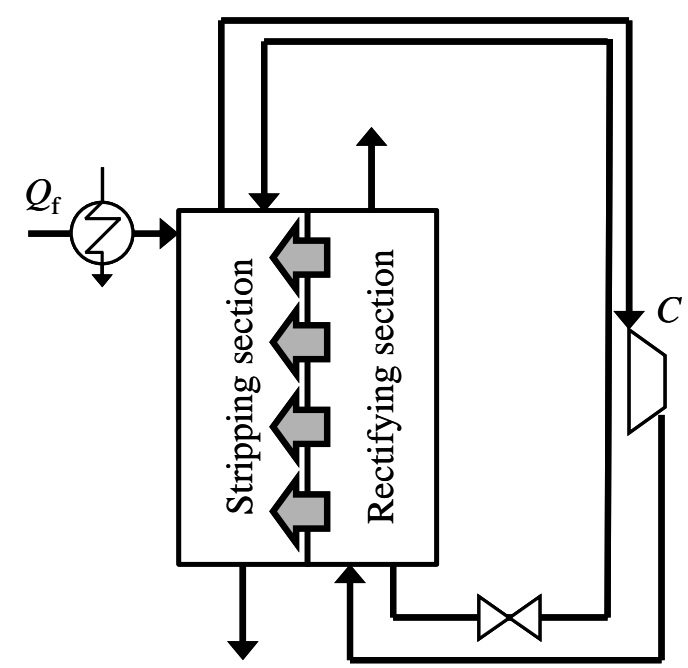

Fig. 2 Schematic diagram of i-HIDiC

Table 1 Standard steady-state operating conditions of binary HIDiC

\begin{tabular}{ll}
\hline Number of stages & 30 \\
Feed stage (Top of stripping section) & 16 \\
Feed flowrate $[\mathrm{kmol} / \mathrm{h}]$ & 100 \\
Feed temperature $\left[{ }^{\circ} \mathrm{C}\right]$ & 87 \\
Feed composition $[$ mole fraction] & \\
$\quad$ Benzene & 0.5 \\
$\quad$ Toluene & 0.5 \\
Product composition [mole fraction] & \\
$\quad$ Top (Benzene) & 0.999 \\
$\quad$ Bottom (Benzene) & 0.001 \\
Pressure at the top of rectifying section & 0.24 \\
[MPa] & 2.3 \\
$P_{\text {ratio }}[-]$ & 3500 \\
$U A[\mathrm{kcal} /(\mathrm{h} \cdot \mathrm{K} \cdot$ stage $)]$ & 111 \\
$V[\mathrm{kmol} / \mathrm{h}]$ & \\
\hline
\end{tabular}

\subsection{Dynamic model}

A dynamic simulator was developed by using ASPEN Custom Modeler ${ }^{\circledR}$ (Aspen Technology, Inc). In the simulation model, the mass balance, energy balance, and pressure drop are taken into account. Changes in liquid holdups are calculated by using the Francis weir equation. The other assumptions are as follows:

1. Tray column is used.

2. Liquid and vapor on each tray are perfectly mixed and in equilibrium.

3. Vapor holdup is negligible.

4. The rectifying section and the stripping section have the same number of trays and exchange the heat between the corresponding trays.

5. Heat transfer is calculated by $U A \Delta T$ where $U$ is the overall heat transfer coefficient, $A$ is the heat transfer area, and $\Delta T$ is the temperature difference between the rectifying section and the stripping section.

In the following sections, binary distillation is 
investigated. The design of HIDiC and its standard steady-state operating conditions are summarized in Table 1. The pressure at the top of the rectifying section is kept at $0.24 \mathrm{MPa}$, and the pressure ratio, $P_{\text {ratio, }}$ is kept at 2.3 by a compressor. The pressure ratio is defined as a ratio between the pressure at the bottom of the rectifying section and that at the top of the stripping section. At the standard steady-state, these pressures are 0.25 and $0.11 \mathrm{MPa}$, respectively.

\section{Analysis of Multiple Steady-States}

Doherty and Perkins (1982) have shown that multiple steady-states never appear in binary distillation with constant molar flow. There exists only one possible steady-state for given reflux flow rate $L$ and boilup vapor flow rate $V$ or any other two independent combinations. However, as pointed out by Jacobsen and Skogestad (1991), simple distillation columns with ideal vapor-liquid equilibrium may display multiple steady-states. They have reported two different sources for the multiple steady-states. The first type is found for columns with mass or volume inputs such as mass reflux instead of molar inputs. The second type depends on the presence of an energy balance in the model.

In HIDiC, the rectifying section and the stripping section are in physical contact, and the pressure in the rectifying section is kept higher than that in the stripping section by using a compressor to enhance heat transfer from the rectifying section to the stripping section through the wall. The energy balance must be taken into account to analyze HIDiC. Therefore, the second type of the sources for the multiple steady-states is investigated in the present work.

\subsection{Instability condition}

When multiple steady-states appear in distillation, there are two stable steady-states and one unstable steady-state in a specific operating condition. The unstable steady-state is a point at which the process is open-loop unstable. For example, product composition jumps from the value at an initial unstable steady-state to the value at another stable steady-state when nominal perturbation is added to the process. The composition cannot be kept close to the initial value without feedback control.

For distillation columns without multiple steady-states, the mole fraction of the most volatile component in distillate $x_{\mathrm{D}}$ is expected to increase when the reflux flow rate $L$ increases and the boilup vapor flow rate from a reboiler $V$ is fixed.

Therefore, a negative slope

$$
\left.\frac{\partial x_{\mathrm{D}}}{\partial L}\right|_{V}<0
$$

corresponds to unstable operating points. This gain can be rewritten as

$$
\left.\frac{\partial x_{\mathrm{D}}}{\partial L}\right|_{V}=\left.\left.\frac{\partial x_{\mathrm{D}}}{\partial D}\right|_{V} \frac{\partial D}{\partial L}\right|_{V}
$$

where $D$ denotes a distillate flow rate. Since $\left.\left(\partial x_{\mathrm{D}} / \partial D\right)\right|_{V}$ is always negative (Jacobsen and Skogestad, 1991), instability occurs when

$$
\left.\frac{\partial D}{\partial L}\right|_{V}>0
$$

This condition means that an unstable operating point appears when the increase of $L$ causes the increase of $D$.

By using the material balance around the condenser

$$
V_{\mathrm{T}}=L+D,
$$

Eq. (3) becomes

$$
\left.\frac{\partial D}{\partial L}\right|_{V}=\left.\frac{\partial V_{\mathrm{T}}}{\partial L}\right|_{V}-1>0
$$

where $V_{\mathrm{T}}$ denotes a vapor flow rate from the top tray to the condenser.

Neglecting changes in liquid enthalpy, the following energy balance equation is derived.

$$
\begin{aligned}
& V_{\mathrm{T}} \Delta H_{\mathrm{T}}^{\mathrm{vap}}=V \Delta H_{1}^{\mathrm{vap}}+Q_{\mathrm{cmp}} \\
& Q_{c}=V_{T} \Delta H_{T}^{\text {vap }} \\
& Q_{r}=V \Delta H_{1}^{\text {vap }}
\end{aligned}
$$

Here $Q_{\mathrm{c}}, Q_{\mathrm{r}}$, and $Q_{\mathrm{cmp}}$ denote heat duty of the condenser, heat duty of the reboiler, and heat input from the compressor, respectively. In addition, $\Delta H^{\text {vap }}$ denotes heat of vaporization.

The instability condition of Eq. (5) is equivalent to

$$
\left.\frac{\partial L}{\partial D}\right|_{V}=\left.\frac{\partial V_{\mathrm{T}}}{\partial D}\right|_{V}-1>0
$$

By substituting Eq. (6) into Eq. (9), the instability condition is given by: 


$$
\begin{aligned}
\left.\left(\Delta H_{\mathrm{T}}^{\mathrm{vap}}\right)^{2} \frac{\partial L}{\partial D}\right|_{V} & =\left.\left.\frac{\partial \Delta H^{\mathrm{vap}}}{\partial x}\right|_{x=x_{\mathrm{B}}} \frac{\partial x_{\mathrm{B}}}{\partial D}\right|_{V} \Delta H_{\mathrm{T}}^{\mathrm{vap}} V \\
& -\left.\left.\frac{\partial \Delta H^{\mathrm{vap}}}{\partial x}\right|_{x=x_{\mathrm{T}}} \frac{\partial x_{\mathrm{T}}}{\partial D}\right|_{V} \Delta H_{1}^{\mathrm{vap}} V \\
& +\left.\left.\frac{\partial Q_{\mathrm{cmp}}}{\partial x}\right|_{x=x_{\mathrm{B}}} \frac{\partial x_{\mathrm{B}}}{\partial D}\right|_{V} \Delta H_{\mathrm{T}}^{\mathrm{vap}} \\
& -\left.\left.\frac{\partial \Delta H^{\mathrm{vap}}}{\partial x}\right|_{x=x_{\mathrm{T}}} \frac{\partial x_{\mathrm{T}}}{\partial D}\right|_{V} Q_{\mathrm{cmp}} \\
& -\left(\Delta H_{\mathrm{T}}^{\mathrm{vap}}\right)^{2}>0
\end{aligned}
$$

The difference between the instability condition of Eq. (10) and that derived by Jacobsen and Skogestad (1991) for conventional distillation columns is the third and fourth terms in the right side of Eq. (10), which are related with the heat input from the compressor. These terms depend on the operation policy of the compressor. In the present work, two types of operation policies are investigated: P1) constant compressor power and P2) constant pressure ratio.

\subsection{Constant compressor power}

Under the operation policy P1, i.e., constant compressor power, heat input from the compressor $Q_{\mathrm{cmp}}$ is also constant.

$$
\frac{\partial Q_{\mathrm{cmp}}}{\partial x}=0
$$

In the present work, power generation efficiency $\eta_{\mathrm{e}}=$ $35.1 \%$, mechanical efficiency $\eta_{\mathrm{m}}=60.0 \%$, and adiabatic efficiency $\eta_{\mathrm{a}}=78.0 \%$ are taken into account for describing the compressor characteristics. The relationship between the compressor power $C$ and the heat input $Q_{\text {cmp }}$ is given by

$$
C \eta_{\mathrm{e}} \eta_{\mathrm{m}}=Q_{\mathrm{cmp}}
$$

The heat input $Q_{\text {cmp }}$ is used for fluid compression and fluid heating, and the ratio of energy for fluid compression to $Q_{\mathrm{cmp}}$ is adiabatic efficiency. Therefore, $Q_{\mathrm{cmp}}$ is constant regardless of the other operating conditions when the compressor power, the power generation efficiency, and the mechanical efficiency are constant.

Under the operation policy $\mathrm{P} 1$, the instability condition is given by:

$$
\begin{aligned}
\left.\left(\Delta H_{\mathrm{T}}^{\mathrm{vap}}\right)^{2} \frac{\partial L}{\partial D}\right|_{V} & =\left.\left.\frac{\partial \Delta H^{\mathrm{vap}}}{\partial x}\right|_{x=x_{\mathrm{B}}} \frac{\partial x_{\mathrm{B}}}{\partial D}\right|_{V} \Delta H_{\mathrm{T}}^{\mathrm{vap}} V \\
& -\left.\left.\frac{\partial \Delta H^{\mathrm{vap}}}{\partial x}\right|_{x=x_{\mathrm{T}}} \frac{\partial x_{\mathrm{T}}}{\partial D}\right|_{V} \Delta H_{1}^{\mathrm{vap}} V \\
& -\left.\left.\frac{\partial \Delta H^{\mathrm{vap}}}{\partial x}\right|_{x=x_{\mathrm{T}}} \frac{\partial x_{\mathrm{T}}}{\partial D}\right|_{V} Q_{\mathrm{cmp}} \\
& -\left(\Delta H_{\mathrm{T}}^{\mathrm{vap}}\right)^{2}>0
\end{aligned}
$$

Assuming no multiplicity for the $D V$ configuration implies that $\left.\left(\partial x_{\mathrm{i}} / \partial D\right)\right|_{V}$ always will be negative (Jacobsen and Skogestad, 1991). In most systems, $\partial \Delta H^{\text {vap } / \partial x}$ will be negative because the heat of vaporization decreases with the fraction of the most volatile component. In addition, $\Delta H^{\text {vap }}, V$, and $Q_{\text {cmp }}$ are always positive. In such cases, Eq. (13) shows that instability appears when the magnitude of $\left.\left(\partial x_{\mathrm{B}} / \partial D\right)\right|_{V}$ is large and $\left.\left(\partial x_{\mathrm{T}} / \partial D\right)\right|_{V}$ is small. This situation happens when the top product is highly pure and the bottom product is relatively impure. Furthermore, Eq. (13) shows that instability appears when $V$ is large and $Q_{\text {cmp }}$ is small. These analysis results are validated later through simulations.

\subsection{Constant pressure ratio}

Under the operation policy P2, i.e., constant pressure ratio $\left(P_{\text {ratio }}\right)$, the instability condition is given by Eq. (10). The only difference between P1 and P2 is the third term in the right side of Eq. (10). The sign of this term depends on the sign of $\left.\left(\partial Q_{\mathrm{cmp}} / \partial x\right)\right|_{x=x_{\mathrm{B}}}$. To keep $P_{\text {ratio }}$ constant under various operating conditions, the compressor power needs to be manipulated. As a result, $Q_{\text {cmp }}$ changes according to the operating conditions including $x_{\mathrm{B}}$. The value of $\left.\left(\partial Q_{\mathrm{cmp}} / \partial x\right)\right|_{x=x_{\mathrm{B}}}$ and the instability condition are investigated through simulations in the next section because the relationship between $Q_{\mathrm{cmp}}$ and $x_{\mathrm{B}}$ is not clear intuitively.

\section{Case Study}

The binary distillation introduced in Section 1 is investigated here again. The design of HIDiC and its standard steady-state operating conditions are summarized in Table 1. Operating conditions where multiple steady-states appear are searched around the standard steady-state operating condition.

\subsection{Constant compressor power}

The analysis conducted in Section 2 is based on the 
assumption that there exists no multiplicity for the $D V$ configuration. Figure 3 validates this assumption, and it is confirmed that $\left.\left(\partial x_{\mathrm{i}} / \partial D\right)\right|_{V}$ is always negative.

For distillation columns without multiple steady-states, top product composition $x_{\mathrm{D}}$ is expected to increase when the reflux flow rate $L$ increases and the boilup vapor flow rate $V$ is fixed. In other words, a negative slope of $\left.\left(\partial x_{\mathrm{D}} / \partial L\right)\right|_{V}$ corresponds to unstable operating points. In this case study, $\left.\left(\partial x_{\mathrm{D}} / \partial L\right)\right|_{V}$ is negative in the region of $L=81.20$ to 81.63 as shown in Figure 4. This result indicates that multiple steady-states appear in the binary HIDiC.

On the basis of Eq. (13), instability is expected to appear when the top product is highly pure and the bottom product is relatively impure. This reasoning is validated from the simulation results shown in Figure 4. The instability condition given by Eq. (3) is also validated through Figure 5, which shows that instability occurs when $\left.(\partial D / \partial L)\right|_{V}$ is positive.

In addition, from Eq. (13), instability is expected to appear when $V$ is large and $Q_{\text {cmp }}$ is small. This reasoning is validated from the simulation results shown in Figures 6 and 7. Figure 6 shows the relationship between product compositions and reflux flow rate when the compressor power is made twice larger than the standard condition. Similarly, Figure 7 shows the relationship between product compositions and reflux flow rate when the boilup vapor flow rate is decreased by half. Under these conditions, unstable operating points do not exist and multiple steady-states do not appear.

From the practical and operational viewpoint, the existence of unstable operating points would not be preferable. The results shown in Figures 6 and 7 indicate that the unstable operating points do not appear and multiplicity can be avoided by adjusting operating conditions such as compressor power and boilup vapor flow rate.

Furthermore, there exists no multiplicity in the conventional distillation column (CDiC), which was discussed by Fukushima et al. (2006). The major difference between $\mathrm{CDiC}$ and HIDiC is the use of compressor in HIDiC. The influence of the difference on the multiplicity can be analyzed by focusing on the effect of the terms related with the compressor power in Eq. (10) or (13).

\subsection{Constant pressure ratio}

Under the operation policy P2, i.e., constant pressure ratio, the instability condition is given by Eq. (10). For further analysis of multiple steady-states in this case, the sign of $\left.\left(\partial Q_{\mathrm{cmp}} / \partial x\right)\right|_{x=x_{\mathrm{B}}}$ needs to be determined.

Figure 8 shows the relationship between the compressor power $C$, which is proportional to $Q_{\mathrm{cmp}}$, and $x_{\mathrm{B}}$ under a constant pressure ratio (P2) and constant boilup vapor flow rate. The sign of $\left.\left(\partial Q_{\mathrm{cmp}} / \partial x\right)\right|_{x=x_{\mathrm{B}}}$ changes at $x_{\mathrm{B}}=0.001$. The slope is negative and very steep when $x_{\mathrm{B}}<0.001$, and it is positive when $x_{\mathrm{B}}>0.001$. Since $\left.\left(\partial Q_{\text {cmp }} / \partial x\right)\right|_{x=x_{\mathrm{B}}}$ is negative large and $\left.\left(\partial x_{\mathrm{i}} / \partial D\right)\right|_{V}$ is negative, the third term on the right side of Eq. (10) is positive large when $x_{\mathrm{B}}<0.001$. Therefore, unstable operating points easily appear when $x_{\mathrm{B}}<0.001$. In other regions, where $x_{\mathrm{B}}>0.001$, instability would not appear.

Figure 9 shows the relationship between product compositions and reflux flow rate under a constant pressure ratio (P2) and constant boilup vapor flow rate. The simulation results validate the above reasoning. In fact, instability appears when $x_{\mathrm{B}}<0.001$.

In this case (P2), multiple steady-states appear in the region of $L=81.4$ to 86.1 , which is significantly wider than that in the previous case (P1). This phenomenon is caused by the existence of the third term in Eq. (10).

The results indicate that $\mathrm{P} 1$ is preferable to $\mathrm{P} 2$ when the unstable operating region should be avoided. However, multiplicity is affected not only by the operation policy but also by control configuration, operating conditions, and design. To improve the operability of the HIDiC or to suggest the specific operation policy, control structure, operating conditions, and design, further investigation needs to be done. This research is the first step to provide useful information for such objectives regarding the multiplicity of the HIDiC.

\section{Conclusions}

In the present work, multiple steady-states in the HIDiC are analyzed. The conditions for making multiple steady-states are derived on the basis of the first principle model of the HIDiC, then the analysis results are validated through simulations. The results show that 1) the instability condition depends largely on the compressor operation policies; 2) in case P1, multiple steady-states appear when the top product is highly pure, the bottom product is relatively impure, vapor flow rate is large, and compressor power is small; 3) in case P2, multiple steady-states appear when the bottom product is highly pure; and 4) multiple steady-states appear in wider range of operation in case $\mathrm{P} 2$ than in case $\mathrm{P} 1$.

This research shows a possible approach to provide useful information for selecting operation policy, control structure, operating conditions, and design of HIDiC from the viewpoint of multiple steady-states. At this stage, the issues discussed are limited. But, it is expected that further results are provided along this direction and they are useful for enhancing the R\&D of the HIDiC.

\section{Nomenclature}

$\begin{array}{ll}C & =\text { compressor power } \\ D & =\text { distillate flow rate } \\ L & =\text { reflux flow rate }\end{array}$




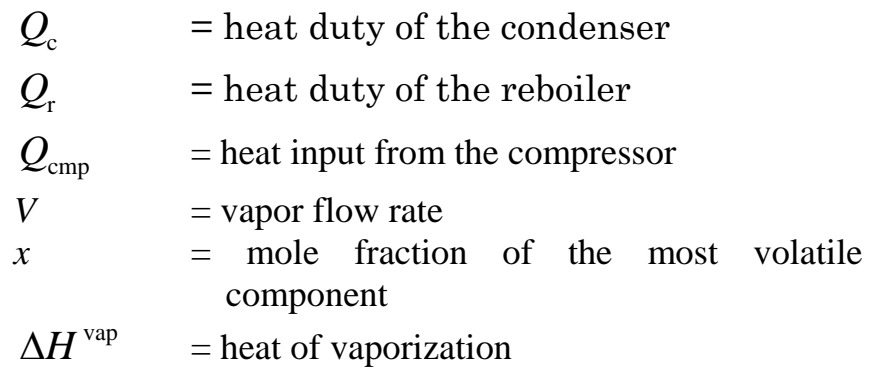

$<$ Subscript $>$

$\begin{array}{ll}\mathrm{B} & =\text { bottoms } \\ \mathrm{D} & =\text { distillate } \\ \mathrm{T} & =\text { top } \\ {[j]} & =j \text { th tray, numbered from the bottom }\end{array}$

\section{Acknowledgments}

This research was partially supported by the New Energy and Industrial Technology Development Organization (NEDO).

\section{Literature Cited}

Doherty, M. F. and J. D. Perkins; "On the Dynamics of Distillation Processes: IV. Uniqueness and Stability of the Steady-State in Homogeneous Continuous Distillations," Chem. Eng. Sci., 37, 381-392 (1982)

Fukushima, T., M. Kano and S. Hasebe; "Dynamics and Control of Heat Integrated Distillation Column (HIDiC),” J. Chem. Eng. Japan, 39, 1096-1103 (2006)

Iwakabe, K., M. Nakaiwa, T. Nakanishi, K. Huang, Y. Zhu and A. Rosjorde; "Analysis of the Energy Savings by HIDiC for the Multicomponent Separation," APPChE, CD-ROM, 0259, Kitakyushu, Japan (2004)

Jacobsen, E. W. and S. Skogestad; "Multiple Steady States in Ideal Two-Product Distillation," AIChE J., 37, 499-511 (1991)

Liu, X. and J. Qian; "Modeling, Control, and Optimization of Ideal Internal Thermally Coupled Distillation Columns," Chem. Eng. Technol., 23, 235241 (2000)

Naito, K., M. Nakaiwa, K. Huang, A. Endo, K. Aso, T. Nakanishi, T. Nakamura, H. Noda and T. Takamatsu; "Operation of a Bench-Scale Ideal Heat Integrated Distillation Column (HIDiC): An Experimental Study," Comput. Chem. Eng., 24, 495-499 (2000)

Nakaiwa, M., K. Huang, M. Owa, T. Akiya, T. Nakane and T. Takamatsu; "Operating an Ideal Heat Integrated Distillation Column with Different Control Algorithms," Comput. Chem. Eng., 22, S389-S393 (1998)

Nakaiwa, M., K. Huang, A. Endo, T. Ohmori, T. Akiya and T. Takamatsu; "Internally Heat-Integrated Distillation Columns: A Review,” Chem. Eng. Res. Des., 81, 162-177 (2003)

Noda, H., N. Kuratani, T. Mukaida, M. Kaneda, K. Kataoka, H. Yamaji and M. Nakaiwa; "Plate Efficiency and Heat Transfer Characteristics in
Heat-Integrated Distillation," Proc. 10th APPChE congress, CD-ROM, 0017, Kitakyushu, Japan (2004)

Takamatsu, T., M. Nakaiwa and T. Nananishi; "The Concept of an Ideal Heat Integrated Distillation Column (HIDiC) and its Fundamental Properties," Kagaku Kogaku Ronbunshu, 22, 985-990 (1996)

Takamatsu, T., M. Nakaiwa, T. Nananishi and K. Aso; "Possibility of Energy Saving in the Ideal Heat Integrated Distillation Column (HIDiC)," Kagaku Kogaku Ronbunshu, 23, 28-36 (1997) 

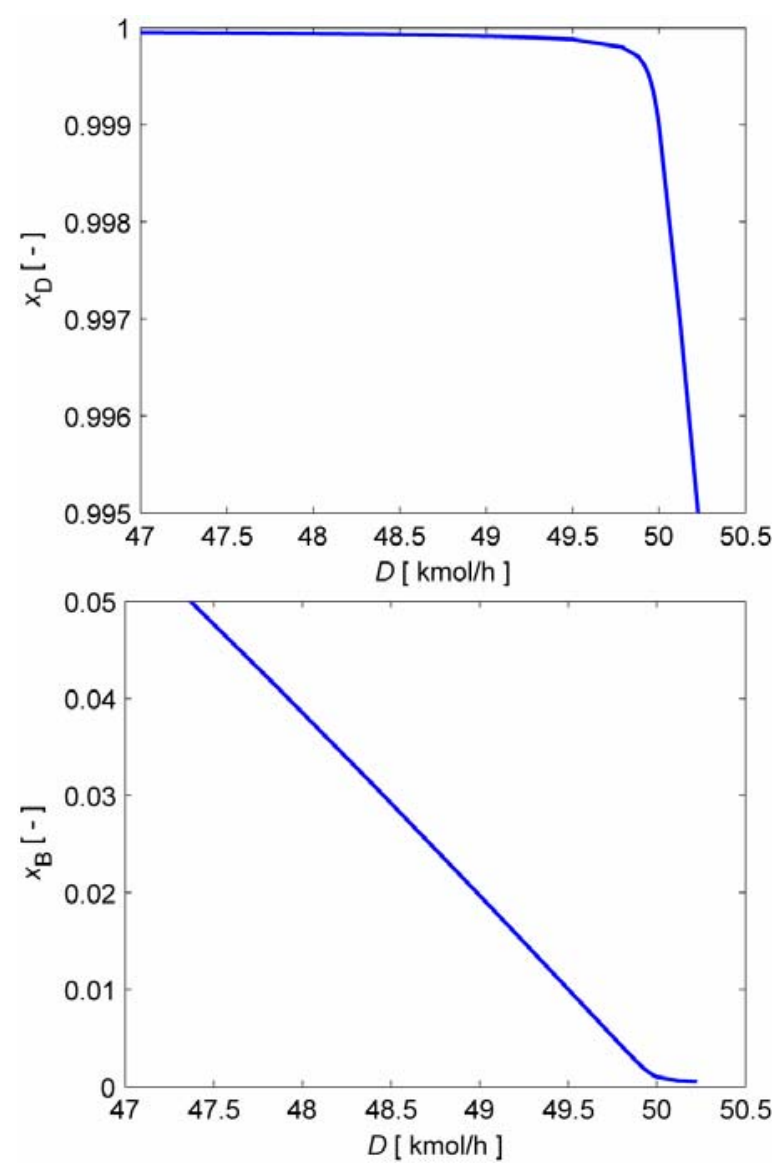

Fig. 3 Relation between product compositions and distillate flow rate under a constant compressor power (P1) and constant boilup vapor flow rate
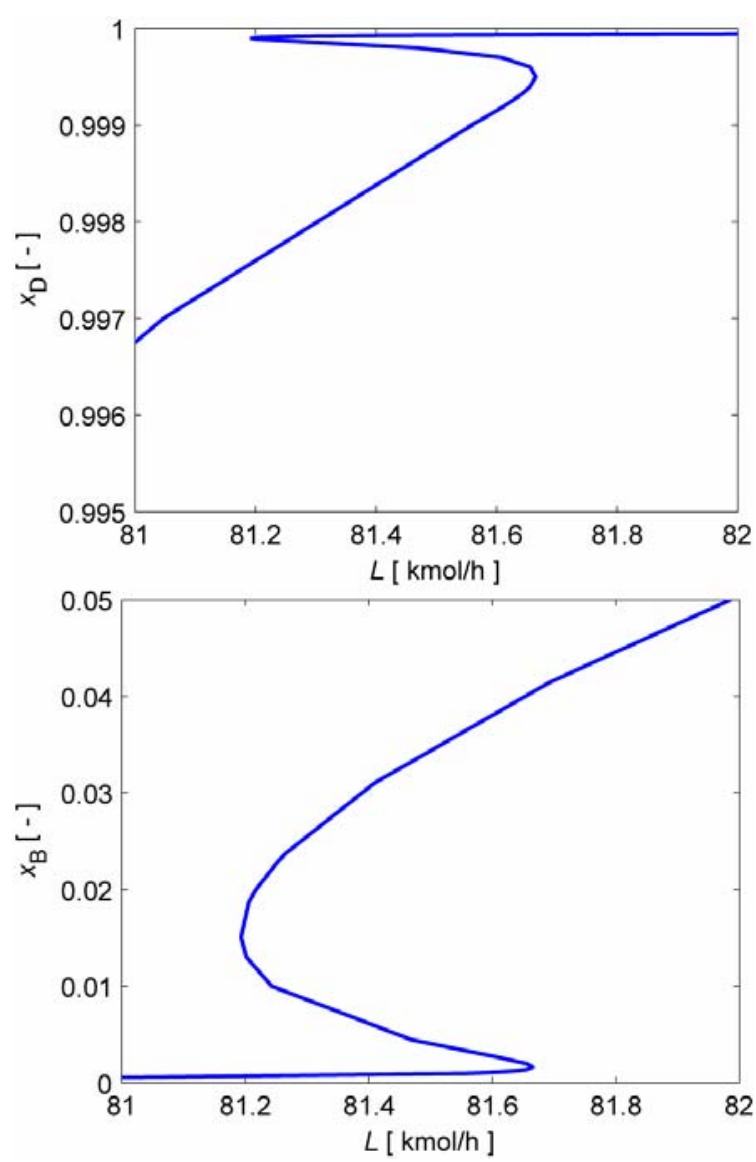

Fig. 4 Relation between product compositions and reflux flow rate under a constant compressor power (P1) and constant boilup vapor flow rate

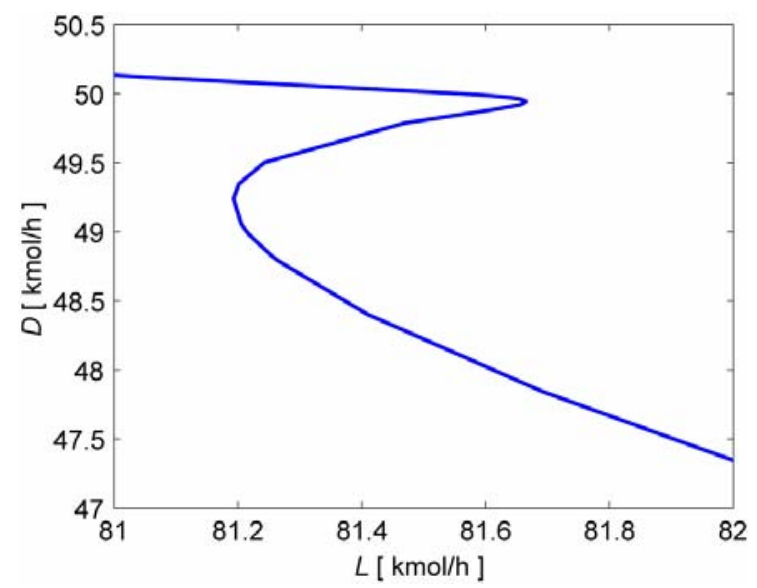

Fig. 5 Relation between distillate flow rate and reflux flow rate under a constant compressor power (P1) and constant boilup vapor flow rate 

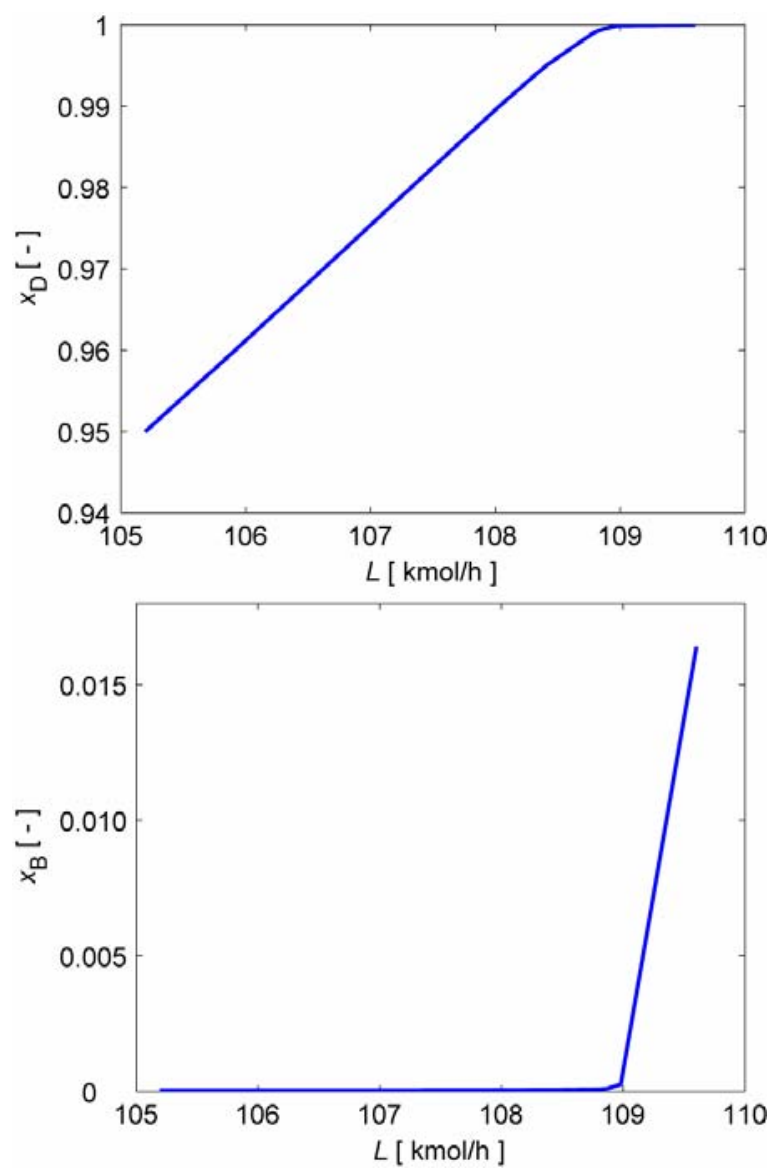

Fig. 6 Influence of compressor power on instability. Relationship between product compositions and reflux flow rate under a high (twice) compressor power and constant boilup vapor flow rate.
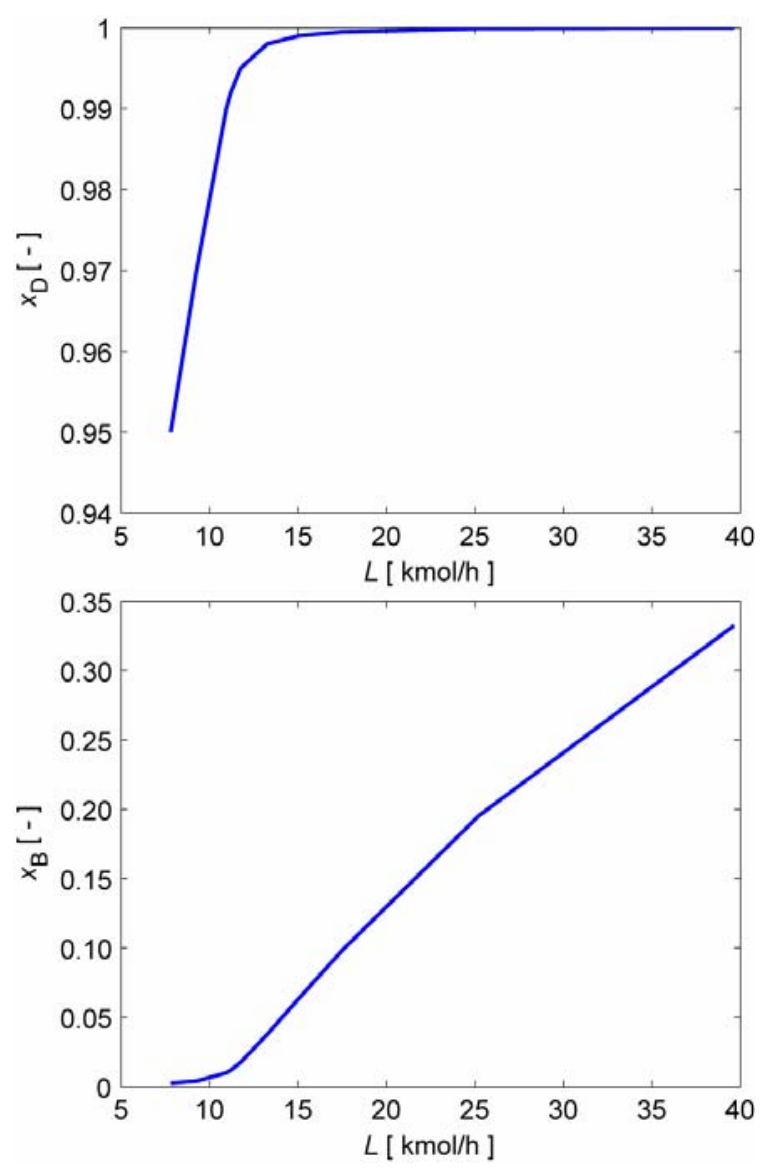

Fig. 7 Influence of boilup vapor flow rate on instability. Relationship between product compositions and reflux flow rate under a constant compressor power and low (half) boilup vapor flow rate.

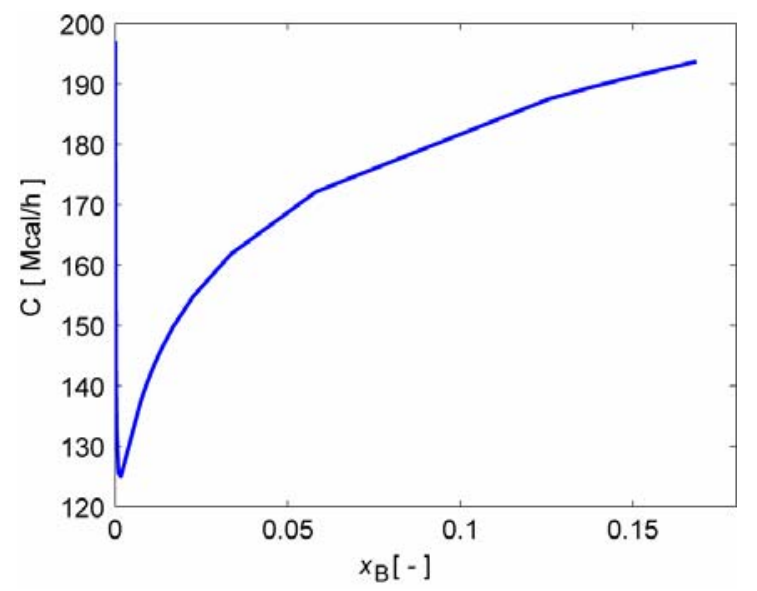

Fig. 8 Relation between compressor power and bottom product composition under a constant pressure ratio (P2) and constant boilup vapor flow rate 

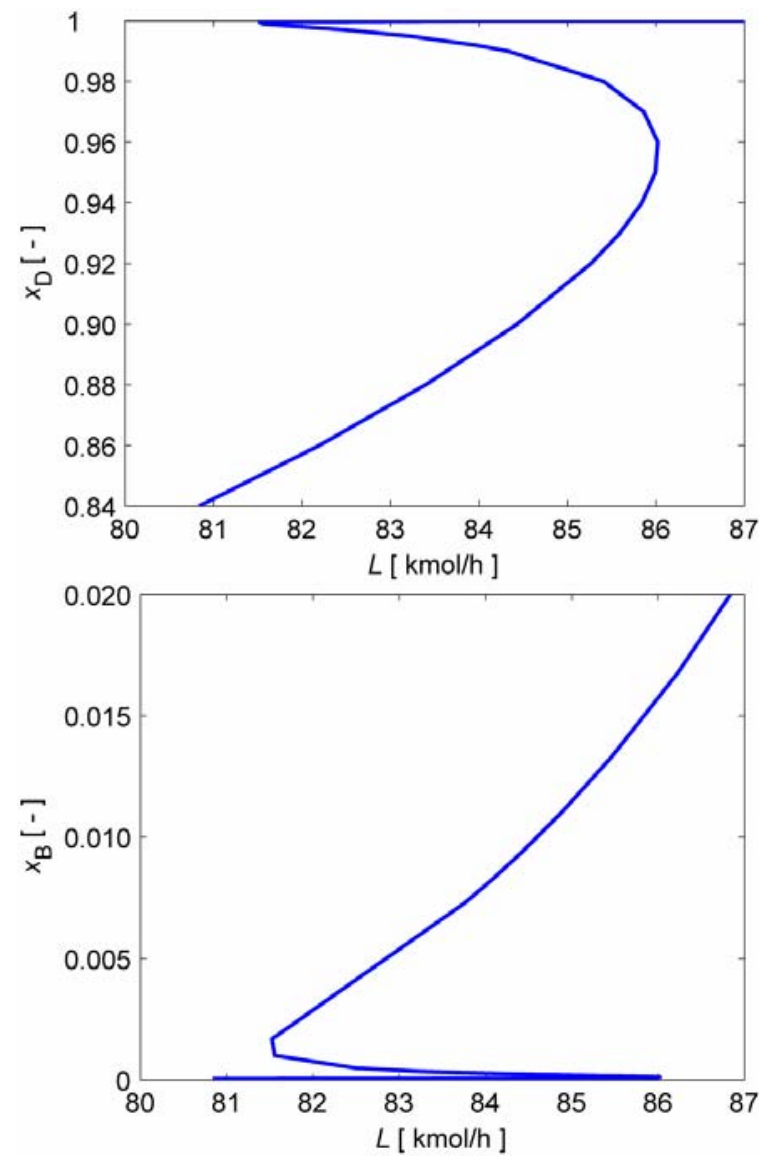

Fig. 9 Relation between product compositions and reflux flow rate under a constant pressure ratio (P2) and constant boilup vapor flow rate 